\title{
Semiótica, enunciação e o discurso na internet: a experiência de ensino de um curso on-line
}

DOl: http://dx.doi.org/10.21165/el.v50i2.2901

\section{Ana Carolina Cortez Noronha ${ }^{1}$}

\section{Resumo}

Este artigo apresenta um curso de extensão universitária oferecido em plataforma digital pela FFLCH-USP em julho de 2020 sobre semiótica, enunciação e o discurso na internet. O curso teve como proposta a apresentação dos conceitos semióticos de análise enunciativa do nível discursivo com base em Fiorin (2002) e Barros (2002) e sua aplicação de análise no discurso encontrado na internet conforme os trabalhos de Barros (2015). Este texto traz considerações sobre o desenvolvimento do conteúdo do curso, reflexões sobre o modo como se deu a interação entre ministrante e participantes e a apresentação de uma análise construída por ambos, em conjunto, no decorrer do curso, sobre conteúdo tirado de redes sociais.

Palavras-chave: ensino de semiótica; enunciação; curso on-line; discurso na internet; regimes de interação.

1 Universidade de São Paulo (USP), São Paulo, São Paulo, Brasil; anacnoronha@yahoo.com; https://orcid.org/0000-0002-4045-677X 


\title{
Semiotics, Enunciation and the Discourse on Internet: the experience of an online course
}

\begin{abstract}
This paper presents an online course that happened in July 2020 on the digital platform, offered by the Department of Extension of the Faculty of Philosophy, Letters, and Human Sciences of the University of São Paulo. It was about semiotics, enunciation, and the discourse on the internet. The course had the purpose of presenting semiotic concepts for the analysis of the enunciation and the discursive level based on Fiorin (2002) and Barros (2002), and how these concepts apply to the analysis of the discourse on the internet according to Barros (2015). This text brings considerations on the development of the course, reflects on the interaction between instructor and participants, and presents an analysis built together by them, during the course, over content extracted from social media.
\end{abstract}

Keywords: teaching of semiotics; enunciation; online course; discourse on the internet; regimes of interaction and meaning.

\section{Introdução}

Este artigo tem por objetivo expor conceitos e ideias que embasaram um curso sobre enunciação e discurso na internet, relatar essa experiência e, a partir dela, buscar algumas considerações sobre esse tipo de interação para o ensino. O curso foi ministrado na edição de inverno de 2020 na Faculdade de Filosofia, Letras e Ciências Humanas da Universidade de São Paulo (FFLCH, USP) e se encontra disponível no canal da FFLCHUSP no YouTube?

Os cursos de extensão da FFLCH USP são voltados ao público geral, configurando um serviço prestado pela universidade à comunidade. Parte-se do conceito de que a universidade deve aproximar-se de um público mais amplo e disseminar o saber para além de seus muros. A oferta de cursos de inverno de 2020 aconteceu em meio ao inesperado evento da pandemia de COVID-19 que atingiu o mundo e, de modo especialmente dramático, o Brasil. Isso fez com que não apenas as matrículas, mas também os cursos acontecessem de forma on-line para o ano de 2020. A procura pelas matrículas, uma vez disponíveis a todo o território digital, foi tão grande que fez com que os servidores da faculdade não aguentassem a demanda e entrassem em colapso, o que obrigou a Extensão Universitária a postergá-las e realizá-las em momentos diferentes para os cursos de extensão oferecidos. Por causa disso também alguns cursos, incluindo

2 Link para a aula 1, parte 1 (a partir da qual se podem encontrar as seguintes): https://youtu.be/ BQP09rNTKyk. Acesso em: 15 set. 2020. 
o nosso, foram postergados, o que, no nosso caso, causou o (único) inconveniente de ter sido oferecido concomitantemente aos outros dois cursos de semiótica que também aconteceram nessa edição de inverno.

A proposta de nosso curso foi a de apresentar o conceito de enunciação a partir do ponto de vista da semiótica francesa e, referente a ele, os conceitos de sintaxe e semântica discursivas com que a semiótica propõe analisar o discurso. Nossa ideia era a de que aqueles que se propõem a análises discursivas com o auxílio da teoria semiótica nem sempre estão familiarizados com essa que entendemos ser uma parte da análise que é mais estrutural, de cunho gramatical, no sentido de organização basilar e estruturadora, que concerne ao exame da sintaxe e da semântica do nível discursivo da teoria. Cremos ser importante esse conhecimento como seria o de uma mecânica da máquina linguística, que faz funcionar os motores da linguagem colocados em funcionamento por um falante enunciador, que deles se utiliza livremente e sem se dar conta. Ao analista, no entanto, cabe conhecer os meandros dessas engrenagens para poder melhor compreender seu funcionamento e os efeitos de sentido que são gerados nos casos de cada pequena alteração, muitas vezes imperceptível para os não-analistas, que se pode operar no fazer linguageiro.

Como enunciatário deste curso, havíamos concebido, a princípio, um público que já tivesse tido algum contato com a teoria semiótica francesa ou com ao menos alguma teoria linguística de texto. Embora isso não tenha sido colocado como uma restrição, ficou como uma recomendação. Mas o que se deu foi um pouco diferente do que havia sido planejado e, como consequência do evento on-line, atingiu-se uma audiência bem mais ampla. Falaremos um pouco também sobre as questões que decorreram dessa amplitude neste texto.

\section{Concepção e organização do conteúdo do curso}

O conteúdo do curso foi pensado para ser dado em oito horas, organizadas em dois dias de aula que foram subdivididos em quatro partes. Para o primeiro dia, (i) o conceito de enunciação para a semiótica francesa e (ii) sintaxe discursiva: os conceitos de debreagem e embreagem de pessoa, tempo e espaço. Para o segundo dia, (iii) semântica discursiva: temas, figuras, o conceito de isotopia e o ator da enunciação e (iv) o discurso na internet: construção sintáxica e semântica do sujeito da enunciação na internet.

Para o desenvolvimento desse conteúdo, nosso apoio se deu principalmente sobre os trabalhos de Diana Barros (2002, 2015), José Luiz Fiorin (2002) e Greimas e Courtés (s/d [1979]). Os exemplos de análise, quando não foram utilizados os que haviam sido propostos por esses autores, foram retirados principalmente de autoras contemporâneas como Adichie (2003), Davis (2016, 2017), Myrtes (2019) e de redes sociais na internet. 
Organizamos uma apresentação de slides com os principais conceitos e exemplos com vistas a trazer clareza e organização didática na exposição. Para esses slides, inserimos as informações de modo mais compacto, privilegiando os exemplos, os esquemas e alguma informação visual que ajudasse o público na memorização do conteúdo. A apresentação foi disponibilizada, ao final do curso, para os participantes em uma pasta compartilhada no Google Drive. O curso foi ministrado utilizando o Google Meet, aplicativo para encontros on-line que permite a participação de até cem pessoas. Nosso público oscilou entre 55 e 70 pessoas durante os dois encontros.

O primeiro momento do curso, após as apresentações da coordenação e da ministrante, foi explicar para os alunos que o curso tinha por objetivo apresentar uma visão introdutória dos estudos sobre a enunciação e sobre as análises do discurso da internet e que nossa intenção era a de apresentar os conceitos, algumas vezes dizer de onde vieram, dizer como eles se desdobram e, por fim, mostrar exemplos de análises. Explicitamos que para se fazer um curso sobre enunciação, com objetivo introdutório e em um tempo curto como o que concebemos, foram necessários recortes sobre o conteúdo e algumas sintetizações, além de não havermos deixado espaço para as discussões teóricas sobre os desdobramentos do conceito de enunciação e sua visão por outras vertentes da semiótica ou mesmo por outras áreas de análise do discurso. Por esse motivo, foi deixada a recomendação, para aqueles que desejassem prosseguir com as análises enunciativas, que posteriormente recorressem aos textos indicados na bibliografia, e para aqueles que precisassem de um pouco mais de conhecimento da semiótica greimasiana, que procedessem ao site do Grupo de Estudos Semióticos, GES-USP ${ }^{3}$, buscando mais especificamente pelo Laborino, que é o grupo de estudos introdutórios.

Figura 1. Slide utilizado para ilustrar que o sujeito da enunciação é constituído por enunciador mais enunciatário. Na imagem, Angela Davis em movimento nas ruas, EUA, 1974

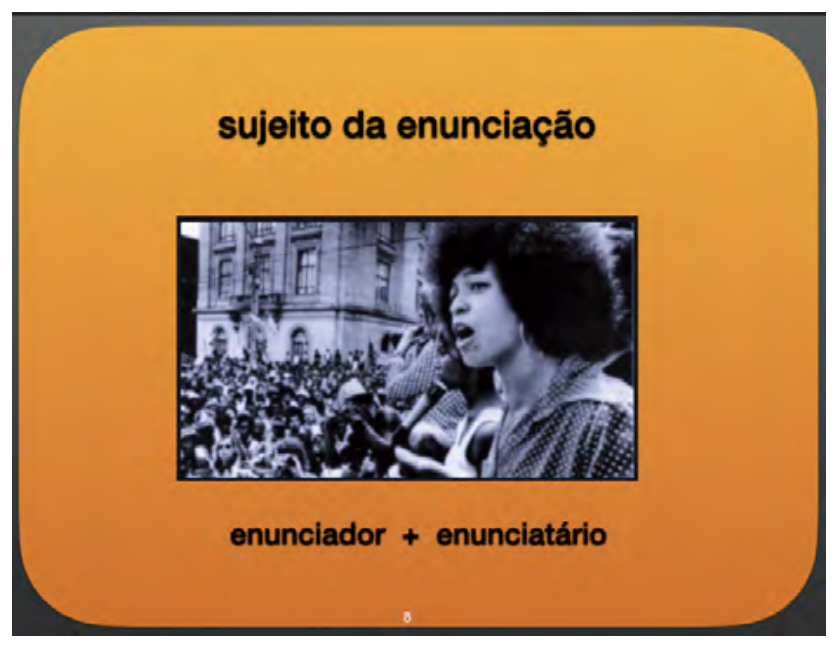

Fonte: https://bit.ly/3hM0EzO. Acesso em: 15 set. 2020.

3 http://semiotica.fflch.usp.br/ 


\section{0 discurso na internet: construção sintáxica e semântica do sujeito da enunciação na internet}

A ideia principal do curso estava voltada para as análises do discurso na internet, com base no trabalho de Diana Barros (2015), cujos trabalhos sobre a complexidade discursiva na internet são desenvolvidos a partir dos estudos da enunciação, da combinação de análises do nível sintáxico e do nível semântico do discurso. Entendemos que eles são de crucial importância para os analistas que, nos dias de hoje, se dedicam a compreender a circulação dos discursos das mais variadas esferas que compõem os subconjuntos desse grande todo compreendido como o mundo on-line. Foi por esse motivo que dedicamos quase três quartos do curso para primeiro explicar os mecanismos que subjazem a essas análises, para, por fim, abordar mais especificamente as análises de Barros.

Assim, depois de apresentar os conceitos sobre a enunciação e de apresentar como a semiótica concebe a sintaxe e a semântica discursivas, incluindo exemplos de análises, a última parte do curso dedicou-se a mostrar como Barros (2015) aplica esses conceitos para analisar o discurso na internet, com o intuito de exemplificar a riqueza de análises que são possíveis a partir deles. A seguir, apresentamos um pouco dessas ideias que foram desenvolvidas no curso. Antes, fazemos a ressalva de que talvez tenhamos cometido um certo exagero ao usar no título do curso "discurso na internet", porque "a internet" corresponde a um vasto mundo, muito diverso e complexo. Esse mesmo exagero encontramos em aproximações diversas, feitas por outros pesquisadores que também buscam estudar os discursos que circulam no meio digital. A generalização, no entanto, vale, tanto no nosso caso como nos outros, pela tentativa de, ao se analisar uma parte do discurso produzido nesse universo, se construir ideias de como se podem erigir bases de análises discursivas para essa totalidade inatingível.

Para adentrar o trabalho de Barros, julgamos importante, previamente, ressaltar um ponto fundamental em relação ao sujeito da enunciação, conceito central para essas análises. Recorremos aqui a um artigo de Juan Alonso, publicado na Estudos Semióticos, que se intitula "As aparências enganam". Diz assim (ALONSO, 2019, p. 157, grifo nosso):

Ora, o desejo de transparência, de acesso à verdade sem restrições, sem obstáculos, por via direta, significa aspirar à possibilidade de enunciados sem as condições de produção, sem enunciação, isto é, significa pretender a palavra sem os sujeitos que a enunciam e sem as diversas modalizações que os caracterizam. Pois bem, a linguística e a semiótica nos ensinam que todo enunciado é resultado de um ato de enunciação que carrega em si os signos de tal ato, os estigmas da presença de um sujeito, de suas condições e de suas competências reais, como desejos, dúvidas, capacidades, conhecimentos, etc. 
A questão que se coloca é que o analista da linguagem não pode jamais cair na tentação de separar o sujeito do discurso produzido e, também, precisa estar ciente de que o sujeito que se encontra no discurso é um simulacro do sujeito enunciador, e nunca um sujeito ontológico. Lembremo-nos que Greimas (1974) nos diz, já em 1973, em palestra proferida aqui no Brasil, que "todos os eu que encontramos no discurso enunciado não são jamais os sujeitos da enunciação, são simulacros".

A partir dessa constatação, ou melhor, desse princípio da análise da enunciação, continuando na questão do sujeito, tem-se que a finalidade da comunicação, como já se sabe, é sempre persuadir. Um enunciador sempre busca estabelecer com seu enunciatário um contrato de fidúcia, que o leva a crer que seu discurso é verdadeiro. Essa crença é construída por meio de estratégias de manipulação que visam a construir um efeito de sentido verdadeiro. É aqui que se coloca o jogo entre o ser e o parecer que constroem o efeito de verdade no texto.

Quando nós pensamos que o efeito de verdade é algo do qual só nos demos conta com o advento da internet e da proliferação de notícias mentirosas e verdades construídas, nos deparamos com Greimas, em Sobre o Sentido // (2014 [1983], p. 131) dizendo que a "verdade" deixou de ser uma adequação à "realidade" referencial para se tornar uma adequação ao nosso próprio universo cognitivo. Trata-se, portanto, de se colocar em evidência, para o analista do discurso, que, no texto, a "verdade" constitui-se por meio de interdefinições, inter-relações de um universo próprio do sujeito ou de um grupo de sujeitos, ou seja, ela passa a ser o produto de uma semiose.

O estabelecimento dessas interdefinições exige reflexão, algo que exige tempo do sujeito e que, contemporaneamente, vem sendo (ainda mais) dificultado pela velocidade acelerada de circulação das informações e pela grande quantidade delas que estão disponíveis. Desse modo, os sujeitos recorrem mais ao crer - que se assenta sobre uma base fiduciária - do que ao saber - cuja existência se assenta sobre uma base lógica (GREIMAS, 2014). O saber exige um estabelecimento lógico de uma rede de conceitos a fim de constituir uma "verdade", enquanto o crer se orienta na direção de se assumir uma rede que já tenha sido estabelecida por outro sujeito. A verdade, aí, emerge como a relação entre o que foi produzido pelo discurso e os valores que nele circulam ${ }^{4}$.

Adentrando o trabalho de Diana Barros (2015) sobre a complexidade do discurso na internet, a segunda questão a ser levada em conta é a de que o discurso na internet traz algumas particularidades que são efeito de sua característica de ser um "termo complexo" entre a fala e a escrita, trazendo características e os valores positivos e negativos associados a ambas. As análises de Barros iniciam-se apoiadas em um estudo anterior

4 Essas ideias encontram-se também desenvolvidas em artigo que publicamos na revista Estudos Semióticos (NORONHA, 2019). 
dela mesma sobre as diferenças entre a fala e a escrita. Estabelecer essa diferença é importante porque a linguagem na internet mistura traços próprios a cada uma delas, apresentando-se quase como um hibridismo de fala e escrita. A escrita, por exemplo, idealmente, é planejada e durativa, e a fala, não planejada, por isso apresenta traços de reelaboração, e é mais pontual. Desse ponto resultam efeitos de mais formalidade para escrita e mais informalidade para a fala. Há ainda as características referentes ao espaço e ao sujeito, analisadas para ambas. Aqui, nos atemos aos efeitos de sentido, conforme especificados pela autora. Para os textos falados e escritos, os efeitos de sentido temporais, espaciais e actoriais são, para a fala, de proximidade, subjetividade, descontração, informalidade, incompletude, simetria, reciprocidade, cumplicidade, e, para a escrita, os de distanciamento, formalidade, completude, assimetria, afastamento. Esses efeitos de sentido têm valorações positivas ou negativas nos diferentes textos.

Considerando, desse modo, os discursos na internet como um termo complexo, especifica-se que os termos complexos são aqueles que se caracterizam pela relação e...e, e correspondem ao eixo dos contrários no quadrado semiótico. Trata-se de uma junção do tipo concessiva: fala (subjetiva, descontraída, incompleta), embora escrita (distante, objetiva, completa). Assim, a comunicação na internet apresenta-se, ao mesmo tempo, próxima e distante; descontraída e formal; incompleta e completa; subjetiva e objetiva. Decorre disso que ela tenha seus sentidos exacerbados, já que engloba as possibilidades de interação das duas modalidades, tanto falada quanto escrita, e daí resultam sua interatividade intensa, a longa conservação de seus conteúdos e a grande extensão de seu alcance (BARROS, 2015).

A partir dessa constatação, Diana Barros parte para o exame da organização enunciativa e veridictória dos discursos na internet para observar como são interpretados, se verdadeiros ou falsos, e também suas características de público ou privado e autoria e anonimato. Para fazer essas análises, são examinadas a sintaxe e a semântica discursivas.

Na sintaxe discursiva, os efeitos dos enunciados feitos em debreagem enunciativa, usando a primeira pessoa, são de aproximação, subjetividade e mesmo de identificação entre enunciador e enunciatário. A relação entre ambos constrói um fazer crer por parte do enunciador, mais do que um fazer saber, e leva o enunciatário a interpretar o discurso da internet como verdadeiro. Mais ainda, nos aponta Barros, que por causa da grande quantidade de saber armazenado na internet e da interatividade acentuada entre os sujeitos - disponíveis, conectados, "a um click de distância" um do outro -, decorrem desse discurso os efeitos de desmascaramento da mentira e de revelação do segredo.

No caso dos recursos semânticos, principalmente o da figurativização do ator da enunciação, as estratégias, nos diz Diana Barros (2015), parecem caminhar na direção contrária àquelas dos procedimentos sintáticos. Os procedimentos sintáticos, com 
o uso de debreagem enunciativa, criam o efeito de aproximação e subjetividade; nos procedimentos semânticos, no entanto, os temas aparecem, muitas vezes, figurativizados por meio de pseudônimos, nem sempre revestidos de nomes próprios ou outras formas de concretização, o que dificulta a formação de totalidades discursivas e a construção plena do ator da enunciação. Como decorrência, tem-se o anonimato, que permite a construção do sujeito da enunciação e até do ator-narrador, mas não a do ator da enunciação pleno, porque não apresenta uma totalidade. Tem-se, daí, um efeito de irresponsabilidade, sancionada negativamente pela sociedade (ibid., p. 25).

Há, ainda, a questão do público versus privado, outro termo complexo que caracteriza o discurso na internet. Tudo indica que, na internet, rompe-se essa distinção, dado que os sujeitos têm um espaço público onde expõem suas posições privadas e fazem isso, muitas vezes, de modo anônimo, o que amplia seu poder por causa da ampla extensão da internet. Aliado ao efeito de sentido que a internet possui como local de armazenagem do saber (popularmente se ouve dizer que "se não está no Google não existe", ou "o Google sabe de tudo"), tem-se as condições para a criação (e circulação da voz) de um sujeito exacerbado, que Diana Barros (2016) caracteriza como decorrente da "intensificação do excesso".

\section{Construção de análise com os participantes}

Depois de explicitados e exemplificados os conceitos, e de termos mostrado como Diana Barros (2015) tem caracterizado o discurso na internet, trouxemos aos participantes do curso alguns tuítes do perfil de Rita Lobo, do site de culinária Panelinha ${ }^{5}$, para que, juntos, pudéssemos realizar alguns esboços iniciais de análise, apontando recursividades figurativas e temáticas que pudessem caracterizar esse ator da enunciação e que mostrassem quais os efeitos de sentido daí decorrentes. Essa experiência foi concebida como uma tentativa de se apresentar aos participantes como se buscam essas recorrências em um conjunto de textos que pudesse ser tomado como corpus. Esses tuítes também nos permitiram apresentar diálogos que se estabelecem entre textos, na medida que continham usos inusitados de objetos do cotidiano e também críticas a acontecimentos políticos recentes. Foi uma opção nossa que o conteúdo das análises que propusemos aos participantes não adentrasse o campo do polêmico, bastante abundante no discurso encontrado na internet, para que pudéssemos nos concentrar na aplicação dos conceitos vistos durante o curso em vez de arriscarmo-nos a adentrar o campo das discussões que nos desviariam do foco. Durante o curso, foram mostrados, mais rapidamente, tuítes em que o mesmo perfil tece comentários irônicos referindo-se a questões políticas do momento, como a sugestão de receitas com laranja no dia em que foi preso Fabrício Queiroz, ligado à família Bolsonaro e suspeito de transações ilícitas. Nossa escolha, nesse caso, foi a de minimizar o risco, mostrando esses tuítes apenas quando já estávamos quase terminando o tempo de análise e já tinham sido feitas as análises dos textos que mostramos a seguir.

5 Na rede social Twitter, perfis @RitaLobo e @Panelinha. 
Os enunciados produzidos nesse perfil e que faziam parte do corpus escolhido mostravam, em um dos textos sincréticos, Rita usando uma abobrinha como telefone, em frente a uma barraca de feira, com a chamada "Rita, help!" (conforme reproduzido na figura 2). A imagem postada estabelece uma relação entre um legume, objeto do universo culinário no qual a apresentadora se insere, ressignificado por causa da posição em que está sendo segurado, da expressão facial de quem o segura e da situação de ajuda à qual remete o enunciado "Rita, help!", que aparece no canto esquerdo, na parte de baixo da imagem. 0 pedido por ajuda contido em "Rita, help!" mais a "abobrinha-telefone" que o sujeito segura remetem ao funcionamento de um helpdesk disponível para atender, a qualquer momento, às solicitações de ajuda por meio de ligações telefônicas de seu público - daí o diálogo apresentado no texto verbal, que se inicia com um "alô".

Figura 2. Imagem utilizada em slide do curso: Rita, help!

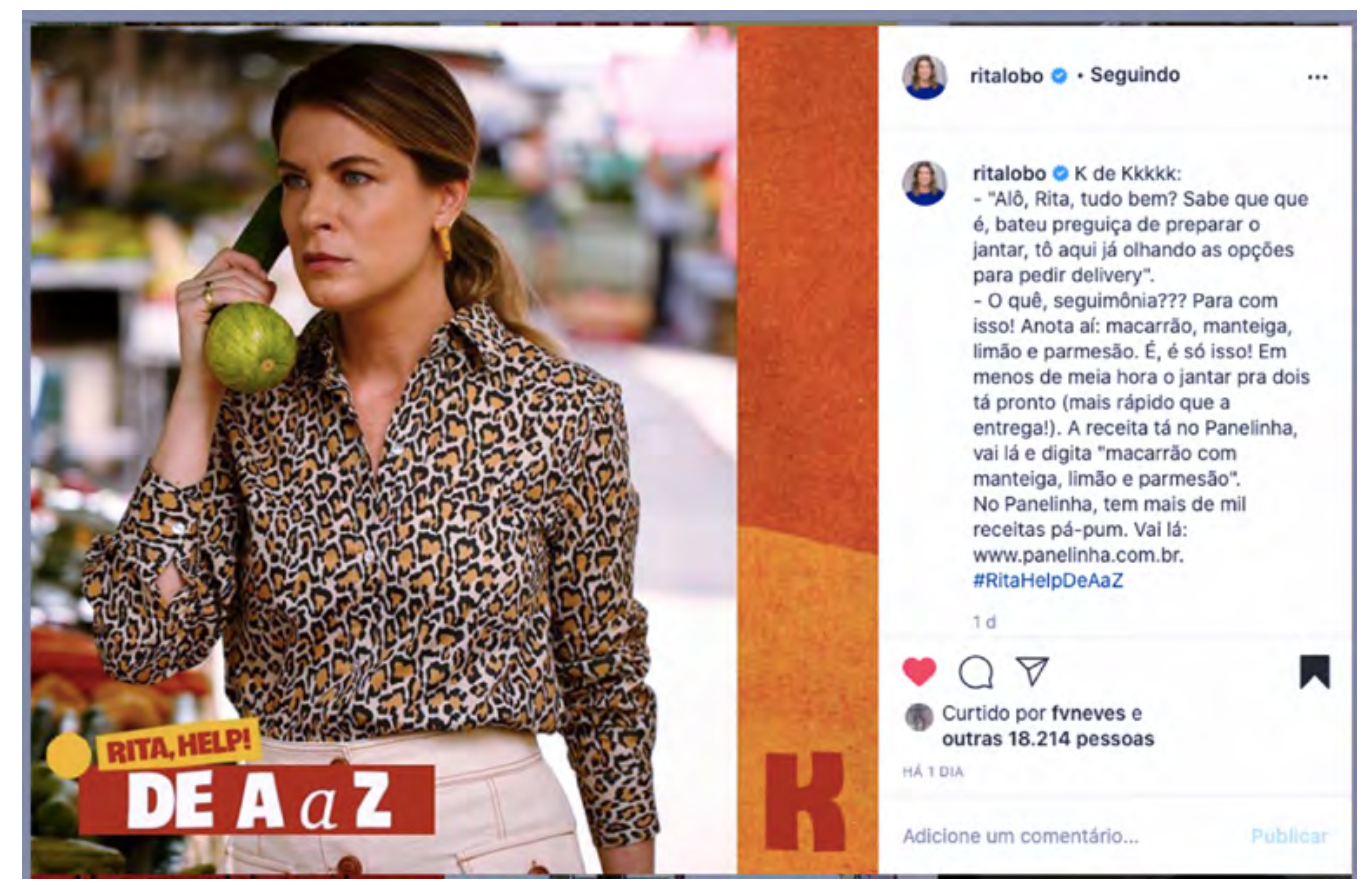

Fonte: Post do perfil de Rita Lobo na rede social Instagram. Coletado em 24 de julho de 2020.

No entanto, o fato de esse objeto ser uma abobrinha também remete à expressão "falar abobrinha" (falar uma bobagem) que se soma à expressão facial algo indignada de Rita na imagem para mostrar a indignação que acomete a apresentadora pelo fato de alguém ter Ihe ligado para dizer que estava "com preguiça de preparar o jantar". A resposta de Rita Ihe recomenda uma receita "pá-pum" e assim se constrói, para o enunciatário, que "ter preguiça de cozinhar" é uma bobagem, é "falar abobrinha", já que a receita é fácil e "mais rápido que a entrega [de comida]", conforme informação do texto verbal. 
Os participantes do curso foram capazes de identificar que o olhar direcionado a alhures, mostrado nas imagens (figura 3), constitui uma debreagem enunciva, e contrasta com o efeito produzido pelo diálogo do texto verbal, uma debreagem enunciativa. Também comentaram sobre a ressignificação que as imagens trazem a objetos cotidianos do universo da culinária, como o uso de uma vasilha em forma de flor como um adereço de cabelo, o uso de uma torta como se fosse uma coroa. Essas rupturas constroem uma isotopia do uso inusitado e ressignificado que esse ator da enunciação Rita Lobo traz para a culinária: cozinhar como algo fácil e rápido ("mais rápido que a entrega"), um ato que se estende à família toda (e não apenas da mulher), cozinhar o simples (arroz e feijão, abobrinha) ao mesmo tempo que essa cozinheira é uma mulher sofisticada. Sofisticação e simplicidade parecem estar na oposição fundamental dos valores dessa totalidade de textos e, a seu modo, os participantes notaram e verbalizaram essa oposição. 0 contraste entre o simples e o sofisticado, entre os objetos do cotidiano culinário e seu uso inusitado também se apresenta na escolha da estratégia sintáxica: debreagem enunciva no texto imagético, enunciativa no texto verbal. Essas primeiras identificações de traços recorrentes que adquirem significados e constroem o ator da enunciação desse conjunto de textos apresentados inserem-se no universo que buscávamos como objetivo de que eles se sentissem competencializados para dar os primeiros passos em uma análise de textos da internet (de postagens de uma rede social, neste caso).

Figura 3. Imagem da gravação da aula do curso Semiótica, Enunciação e o Discurso na internet, de 30 de julho de 2020

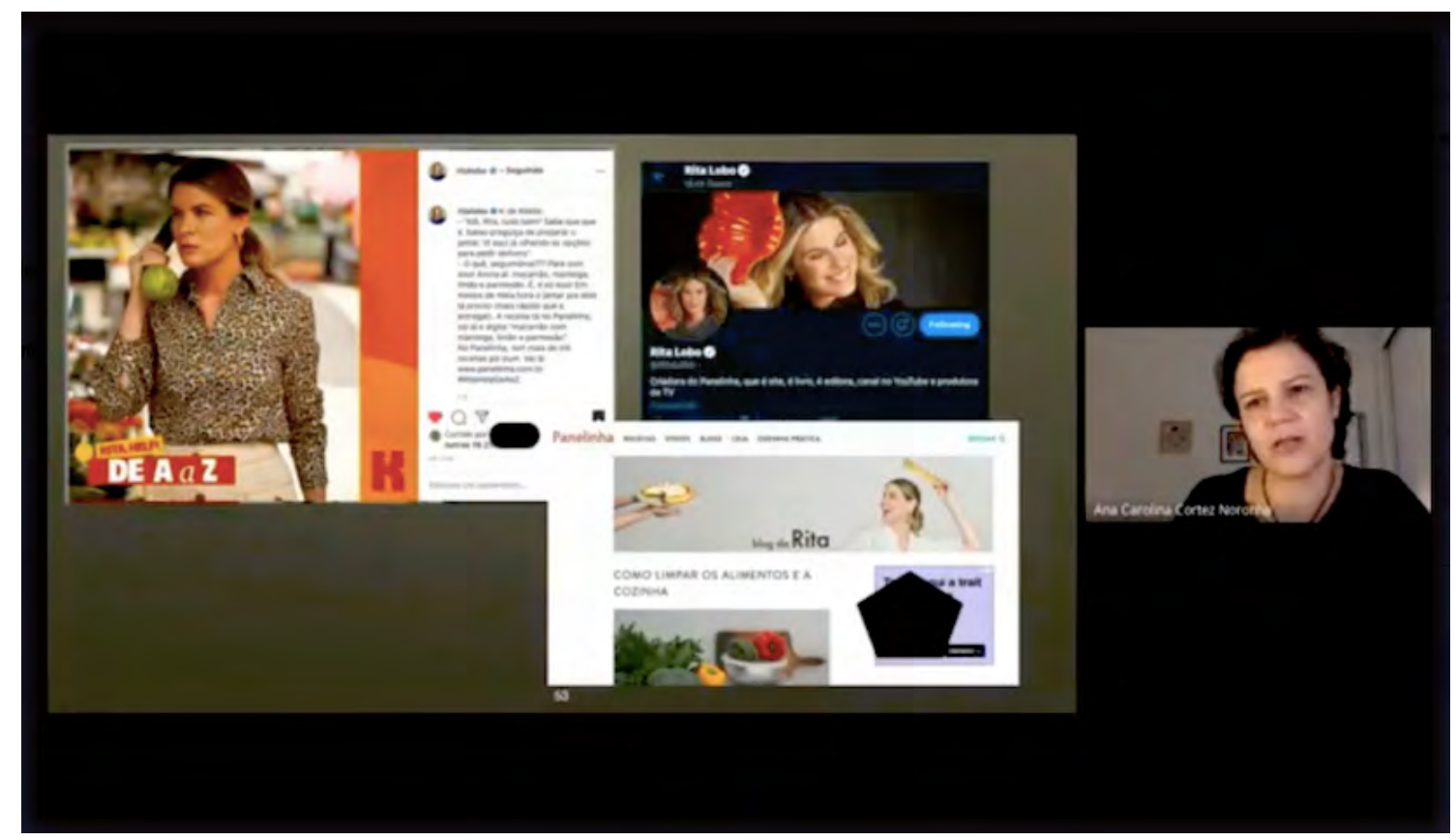

Fonte: Arquivo próprio 


\section{Das interações acontecidas no curso}

O curso foi ministrado por meio de encontros síncronos utilizando a ferramenta de reunião on-line Google Meet. Esse tipo de encontro permite que ministrante e participantes estejam no mesmo horário e na mesma sala virtual, o que, em tese, se entende como uma aula. Por não partilharem do mesmo espaço físico, mas sim do mesmo tempo, pode-se pensar que essa aula virtual fica entre uma aula presencial, na qual os sujeitos ocupam os mesmos espaços e tempos, e uma aula gravada, em que o tempo da aula gravada pelo professor é anterior ao da aula assistida pelo aluno.

Em um primeiro momento, combinou-se com os alunos que eles permaneceriam com seus microfones desligados e que proporiam suas perguntas quando quisessem e por meio do bate-papo escrito. Ao mesmo tempo, eles foram bastante incentivados a proporem suas dúvidas e questões. Nossa estratégia foi ler as colocações dos participantes enquanto íamos fazendo a exposição dos slides e essa dinâmica, a nosso ver, trouxe a vantagem de tornar o desenrolar do curso mais parecido com o de uma aula, pela interação, apesar da grande demanda de atenção para se dar conta do desenvolvimento do curso e, ao mesmo tempo, olhar para o bate-papo e ir respondendo ao que era colocado. Consideramos que essa abertura tenha sido fundamental para que o curso pudesse ir se desenvolvendo de forma mais significativa para os participantes, e a partir dela foi possível explicitar alguns pontos que nos teriam passado despercebidos se não tivessem sido questionados (como uma questão feita sobre os dêiticos, nomenclatura não tão evidente para os alheios à área de letras, que havia nos passado despercebida). Porque se, normalmente, já há dificuldades na produção do discurso de ensino no que se refere à concepção de um enunciatário, em um curso on-line aberto a toda a comunidade digital, essa concepção tende a se tornar ainda mais imprecisa, pela amplitude de origem do auditório e de conhecimento prévio que ele traz consigo. É sabido que os sujeitos apreendem aquilo que estão prontos para compreender, cada um a seu tempo, e por isso, são bem-vindas flexibilidade e abertura para que os enunciatários possam se colocar e, assim, ajudar a construir o (dis)curso.

Eric Landowski, em Interações arriscadas (2014), propõe refletir sobre a relação entre a construção do sentido e as modalidades de interação com base na noção de risco. Para isso, ele desdobra o nível narrativo para além dos regimes da programação e da manipulação, já conhecidos, estendendo-os para os regimes do ajustamento e do acidente $^{6}$. Nesses quatro regimes de interação, perseguindo-se o caminho do menos para o mais arriscado, vai-se da quase ausência de risco (programação), cujo regime de sentido é o "insignificante", para o risco limitado (manipulação), num regime de sentido de "ter significação", depois para o ajustamento, cujo regime de sentido é o do "fazer

60 regime da programação opera sob a lógica da regularidade, o da manipulação, sob a lógica da intencionalidade, o do ajustamento, sensibilidade e o do acidente funda-se sobre a lógica da aleatoriedade. 
sentido" para, por fim, chegar-se ao regime do acidente, da "insensatez". Esses regimes de interação não são estanques e perfazem percursos, que podem ir da programação, passando pelo ajustamento e chegando até o acidente ou, ao contrário, iniciar-se no acidente, passando pela manipulação para chegar até a programação. Na sala de aula, eles podem acontecer simultânea ou alternadamente (LANDOWSKI, 2016).

Durante a parte inicial da aula, em que se fez a exposição de conceitos, o regime de interação (LANDOWSKI, 2014) em que se encontram enunciador e enunciatário se situou mais entre programação e manipulação, no eixo da prudência. Entretanto, quando se chegou à parte final do curso, durante a atividade de análise conjunta descrita no item anterior, a interação movimentou-se em direção ao ajustamento, pois as questões se intensificaram, a participação ficou mais ativa e houve, pelo lado dos participantes, até mesmo o uso do microfone para a troca de ideias.

Nossa ideia, ao incentivarmos a participação e ao propormos a análise conjunta de um pequeno corpus selecionado, foi a de minimizar o risco da falta de sentido que se corre em um curso on-line pelo excesso de programação. Ao não ver os participantes, o ministrante do curso arrisca seguir apesar dos alunos e assim fazer da aula algo que esteja mais caracterizado como uma aula gravada, assíncrona, do que uma aula síncrona, como era o caso. Dadas as dificuldades de o compartilhamento dar-se apenas pelo espaço virtual, o reforço da interação por meio do diálogo buscou intensificar o efeito de proximidade.

O ponto positivo da construção conjunta de uma análise de um texto da internet, como fizemos, é que por meio dela é possível mostrar o modo de se iniciar uma análise sobre um corpus e acreditamos que também seja de construir com os participantes uma certa consciência da própria capacidade de análise, guiando-os conforme iam fazendo suas sugestões, buscando aplicar a elas a metalinguagem utilizada pela semiótica, buscando clarear os conceitos recém vistos à luz dessa teoria. O ponto negativo é que se trata de uma abordagem que dá bastante amplitude para a sugestões dos mais variados matizes analíticos, e a análise avança pouco e lentamente, caso se comece a considerar um número maior de sugestões de participantes. Por outro lado, considerá-las constitui importante estratégia de interação. Também não foi possível, no espaço e tempo do curso e no modo escolhido de se fazer a análise, um aprofundamento de questões que se mostraram no corpus que havíamos selecionado.

Sempre há alguma complexidade em se lidar com o risco inesperado contido nas sugestões que podem aparecer. No entanto, pode-se dizer que lidar com o inesperado se apresenta como uma característica esperada de alguém que se disponha a adentrar uma sala de aula (presencial ou virtual). Se tivéssemos trazido uma análise pronta, teríamos ganhado em profundidade e precisão analíticas, mas provavelmente não teríamos obtido resultados tão bons de interação. Essa abertura do convite para a análise em construção funcionou como estímulo à participação e à exposição ao risco daqueles que são mais 
iniciantes. Pelo fazer sentir do ajustamento, nessa parte da aula, fomos acolhendo as sugestões que os participantes iam fazendo pela ferramenta de bate-papo, ao mesmo tempo em que esses iam formulando suas perguntas mediante a apresentação das imagens e a condução da análise. Embora, nesse regime de interação, haja maior risco, tem-se um sujeito que leva em conta o outro como um sujeito também dotado de um querer, o que seria um modo não apenas de persuasão, mas de interação, mais desejável porque mais democrático e inclusivo. Lembrando, ainda, que no ajustamento abrem-se perspectivas mais amplas de criação de sentido. Se a análise estivesse pronta e tivesse sido apresentada aos participantes, a aula teria permanecido no regime da programação, da regularidade, e da manipulação, no exercício da persuasão.

Assim, de nossas observações sobre o desenvolvimento do curso, pode-se perceber que a abertura em direção ao outro, o participante, explicitada por meio de incentivo constante à participação por meio de perguntas e pelo acolhimento delas, foi fundamental para construir a força de um discurso que construiu o efeito de proximidade entre enunciador e enunciatário. Essa abertura ao diálogo consistiu em uma estratégia de persuasão, por meio do qual se buscou a construção do curso como um espaço de inter-relação. Isso foi feito durante todo o curso, desde o início, quando foi solicitado aos participantes que informassem seus locais de origem e área de estudos, teve continuidade durante as exposições, com a leitura dos comentários e perguntas e teve, nessa parte de análise que se deu no final do curso, um momento no qual se intensificou a troca entre os sujeitos. Esse foi o modo como concebemos que seria possível atenuar a aridez que um curso on-line pudesse ter, principalmente nas condições de distanciamento social em julho de 2020. A aula on-line precisa de interação, caso contrário ela poderia ser um vídeo gravado e disponibilizado em algum lugar, e teria menos características de uma aula, pendendo mais para uma exposição. É nessa dualidade entre a interação espontânea (mais arriscada, do fazer sentido), que se tem na aula síncrona, e o programado (menos arriscado), da aula assíncrona, que reside a caracterização de uma aula (presencial ou on-line).

\section{Considerações finais}

Houve algumas coisas que pensamos poderem ser feitas de outro modo, depois de passado o curso. Teria sido útil, quando entramos em contato com os participantes para Ihes dizer que estavam inscritos e que enviaríamos o link da sala do Google Meet na véspera, que tivéssemos já disponibilizado algum material de leitura, para aqueles que tivessem tido essa curiosidade ou vontade de chegar com maior preparo. Isso teria permitido um maior conhecimento do que tratava o curso e possivelmente teria impactado positivamente no aprendizado, uma vez que, para aqueles que chegaram com pouca ou nenhuma informação sobre o assunto, o curso ficaria como um segundo contato, depois de um primeiro via leitura. Ainda que nossa proposta não tivesse previsto avaliação do aprendizado, é conhecida a eficácia dessa abordagem para os resultados. O fato de os participantes terem origem em diferentes áreas do saber e partirem de diferentes níveis 
de conhecimento sobre o tópico não foi um impeditivo para a transcorrência do curso, ainda que certamente tenha influenciado bastante no modo como cada um aproveitou as informações.

Teria sido interessante também ter solicitado e recolhido um feedback com perguntas pensadas de antemão, feitas com mais preparo e maior elaboração e endereçadas aos participantes para que expressassem sua percepção a respeito do curso e da própria absorção de informações, com a finalidade de melhorarmo-lo em próximas edições (caso ocorram). Isso poderia ter sido feito por meio de algum formulário pronto do Google, já que tínhamos os e-mails de todos os participantes e estávamos nos comunicando por meio dessa plataforma. O que fizemos foi apenas, ao final, agradecê-los pela participação e nesse momento recolhemos algumas considerações breves que eles fizeram espontaneamente. Essas considerações foram positivas, como tendem a ser, via de regra, pois aqueles que têm críticas dificilmente as colocam nesse espaço breve e fortuito do final da aula. Tendemos a achar, no entanto, que se tratou de uma experiência bastante positiva.

Nossa ideia, como colocado a princípio, era de colocar aqueles que se interessam em contato com a análise do nível discursivo da semiótica francesa para, em seguida, mostrar o trabalho de Diana Barros sobre o discurso na internet. Em tempos de distanciamento social, como temos no momento por causa da pandemia do vírus SARSCoV-2, e de aumento do uso dos espaços digitais para convivência, trabalho e ensinoaprendizagem, compreender as especificidades do discurso na internet passa a ser ainda mais importante. Essa é uma mudança que permanecerá e já vem ganhando o nome de "ensino híbrido", de mistura de modos presencial e virtual. Desse modo, esperamos que este texto que ora se apresenta possa ter, de algum modo, não apenas registrado essa experiência, mas também contribuído com algumas ideias sobre cursos on-line para que outros possam se aventurar por esses caminhos.

\section{REFERÊNCIAS}

ADICHIE, C. Hibisco roxo. São Paulo: Cia. das Letras, 2003.

ALONSO ALDAMA, J. As transparências enganam. Estudos Semióticos [on-line], São Paulo, v. 15, n. 1. p. 152-161, ago. 2019.

BARROS, D. L. P. de. Teoria do Discurso. Fundamentos Semióticos. São Paulo: Humanitas, 2002.

BARROS, D. L. P. de. A complexidade discursiva na internet. CASA: Cadernos de Semiótica Aplicada, Araraquara, v. 13, n. 2, p. 13-31 2015. 
BARROS, D. L. P. de. Estudos discursivos da intolerância: o ator da enunciação discursivo. Cadernos de Estudos Linguísticos, Campinas, n. 58:1, 2016.

CORTINA, A.; MARCHEZAN, R. Teoria semiótica: a questão do sentido. In: MUSSALIM, F.; BENTES, A. C. (org.). Introdução à linguística: fundamentos epistemológicos. v. 3. Campinas: Cortez, 2011. p. 393-437.

DAVIS, A. A liberdade é uma luta constante. São Paulo: Boitempo, 2017.

DAVIS, A. Mulheres, raça e classe. São Paulo: Boitempo, 2016.

DISCINI, N. O estilo nos textos. São Paulo: Contexto, 2004.

FIORIN, J. L. As astúcias da Enunciação. São Paulo: Ática, 2002.

GOMES, R. de S. Crise de veridicção e interpretação: contribuições da Semiótica. Estudos Semióticos [on-line], São Paulo, v. 15, n. 2, p. 15-30 dez. 2019.

GREIMAS, A. J. A Enunciação (uma postura epistemológica). Cópia PDF traduzida por Jean Cristtus Portela e Maria Lúcia V. P. Diniz do texto original: L'énonciation (une posture épistemologique). Significação - revista brasileira de semiótica, 1974. Disponível em: http://semiotica.fflch.usp.br/sites/semiotica.fflch.usp.br/files/u45/enunciacaoGreimas.pdf. Acesso em: 20 jun. 2021.

GREIMAS, A. J.; COURTÉS, J. Dicionário de Semiótica. São Paulo: Cultrix, [1979].

LANDOWSKI, E. Regimes de sentido e formas de educação. Tradução Luíza Silva. Entreletras, Araguaína, v. 7, n. 2, p. 8-14, jul./dez. 2016.

LANDOWSKI, E. Interações Arriscadas. São Paulo: Estação das Letras e Cores, 2014.

MYRTES, A. Mauricea. São Paulo: Editora Edith, 2019.

NORONHA, A. C. C. Considerações semióticas sobre o uso de tecnologia digital em salas de aula. Estudos Semióticos, v. 15, n. 2, p. 280-291, 2019. 